\title{
NEW TECHNIQUES FOR COUNTING AND ISOLATING FREE LIVING NEMATODES FROM SMALL SOIL SAMPLES AND FROM OAK FOREST LITTER *)
}

\author{
BY \\ G. MINDERMAN \\ (Institute for Biological Field Research, T.N.O., Arnhem, The Netherlands)
}

In an article on aims and methods of ecological research on nematodes (Minderman, I956) five techniques are mentioned. Four of these methods are described below. A description of the fifth, the preparation of sections of soil samples suitable for microscopical investigation at high magnifications, will be published elsewhere. The methods described here are:

I. Two techniques for quantitative investigations of eelworms in small soil samples.

a. a staining method.

b. a centrifugal flotation method.

2. Two techniques for quantitative investigations of nematodes in forest litter.

a. a modification of the Baermann funnel method.

b. a bleaching and staining technique.

QUANTITATIVE INVESTIGATIONS OF EELWORMS IN SMALL SOIL SAMPLES

a. The staining method. For investigations on the ecology of soil inhabiting nematodes reliable quantitative techniques are needed for the determination of the numbers of all species of nematodes present in small samples, $1 / 4 \mathrm{ml}$ to $\mathrm{I} \mathrm{ml}$ in size. The technique must be applicable to different types of soil including peat. None of the methods described in literature was found to be wholly satisfactory. The best results were obtained when using the direct examination technique described by STöcKLI (I943). This is a time consuming method, however, which is also very tiring to the eyes. A great improvement was obtained by combining it with the lactophenol cottonblue staining of the nematodes as described by GOODEY (1937), for the demonstration of nematodes in plant tissue. In this way the nematodes

*) Received for publication: September 15, 1956. 
in the soil sample are stained deep blue, whereas the mineral and organic soil particles remain unstained. The nematodes are then readily visible between these particles and it is much easier to count and to collect the smallest specimens under low power $\left(5^{\circ} \times\right)$ than when Stöcklı's technique is used.

Procedure

I. A soil sample of $1 / 4$ of $1 / 2 \mathrm{ml}$. is placed on filter paper in a filter holder as shown in PI. XXI.

2. A solution of $0,05 \%$ cotton blue or acid-fuchsin in lactophenol is heated to about $70^{\circ} \mathrm{C}$ and poured on the sample.

3. After 3-5 minutes the nematodes have absorbed sufficient stain and the lactophenol cotton blue is sucked from the soil sample through the filter paper by means of a suction pump. Some plain lactophenol is poured on afterwards and also sucked through in order to remove all excessive stain.

4. A small amount of lactophenol is added to the sample which is then transferred to a counting dish using the tip of a feather as a brush.

5. Under a dissecting microscope $\left(5^{\circ} X\right)$ the nematodes are picked from between the soil particles and transferred from the counting dish to drops of lactophenol on slides by means of a hair fixed to a glass rod. The drops are covered afterwards by cover slips, which are sealed with Thorne's Zut (Glyceel).

The filterpaper used is Delta No 350, a hard, smooth and tough quality, which is commonly used for filtering strong acids or alkaline solutions. It does not give of $f$ loose fibres.

In the identification of the nematodes mounted in lactophenol the phase contrast microscope is a valuable help.

\section{b. The centrifugal flotation method}

The staining technique is very valuable as a method for checking the relability of other techniques but it takes to much time to be used as a routine method for the investigation of large numbers of samples. The centrifugal flotation method described below requires much less time and is therefore more appropriate for this purpose. The technique proved to be applicable to samples of sizes between $1 / 4 \mathrm{ml}$ and $4 \mathrm{ml}$, depending on the humus content of the soil.

Sandy soils and clay soils are treated in different ways. 
Equipment:

I. A centrifuge with tubes of $50 \mathrm{ml}$ and $100 \mathrm{ml}$ and fitted with a control to permit the number of revolution per minute to be regulated. A centrifuge with $15 \mathrm{ml}$ tubes, driven by hand, may also meet the requirements of the method in a number of cases.

2. An electric stirrer, with a propeller small enough to operate in $5^{\circ}$ $\mathrm{ml}$ centrifuge tubes.

3. A solution of magnesiumsulphate in water, spec. gravity 1.25 .

4. Filter holders and filter paper as described above.

5. Counting dishes, preferably with sloping sides.

Procedure.

I. For sandy soils.

I. The sample is transferred to a $50 \mathrm{ml}$. centrifuge tube which is filled with magnesiumsulphate solution up to $1 / 4$ or $1 / 2$ of its volume. This tube is clamped under the stirrer, which is run fast enough to suspend the particles of the soil sample in the solution. This stirring process takes five minutes.

2. The tube is taken from the stirrer, some more mag. sulph. solution is added until the tube is nearly filled and then placed in the centrifuge for one minute. After about 30 seconds the number of revolutions must be constant at about $I_{500}$ revolutions per minute. It is stressed here that centrifuges may differ in the time needed to reach top speed and the figures given here may be taken as a guide but will vary with other machines.

3. After centrifuging, the clear supernatant part of the liquid is poured into a filterholder, taking care that the tube is rotated on its longitudinal axis to ensure that the parts adhering to the wall of the tube also come on to the filter. This part of the liquid is then sucked through by means of a pump.

4. More mag. sulph. solution is added to the heavy portion which remains in the tube. This is now shaken or stirred for a short time and is followed by centrifuging as in paragraph 2 above.

5. As paragraph 3, using the same filter.

6. The residue on the filter is washed with water and then stained by pouring over it a hot solution of $0.05 \%$ acid fuchsin or cotton blue in lactophenol.

7. After five minutes the dye is sucked through and the residue washed with plain lactophenol.

8. The residue is transferred from the filter into a counting dish. 


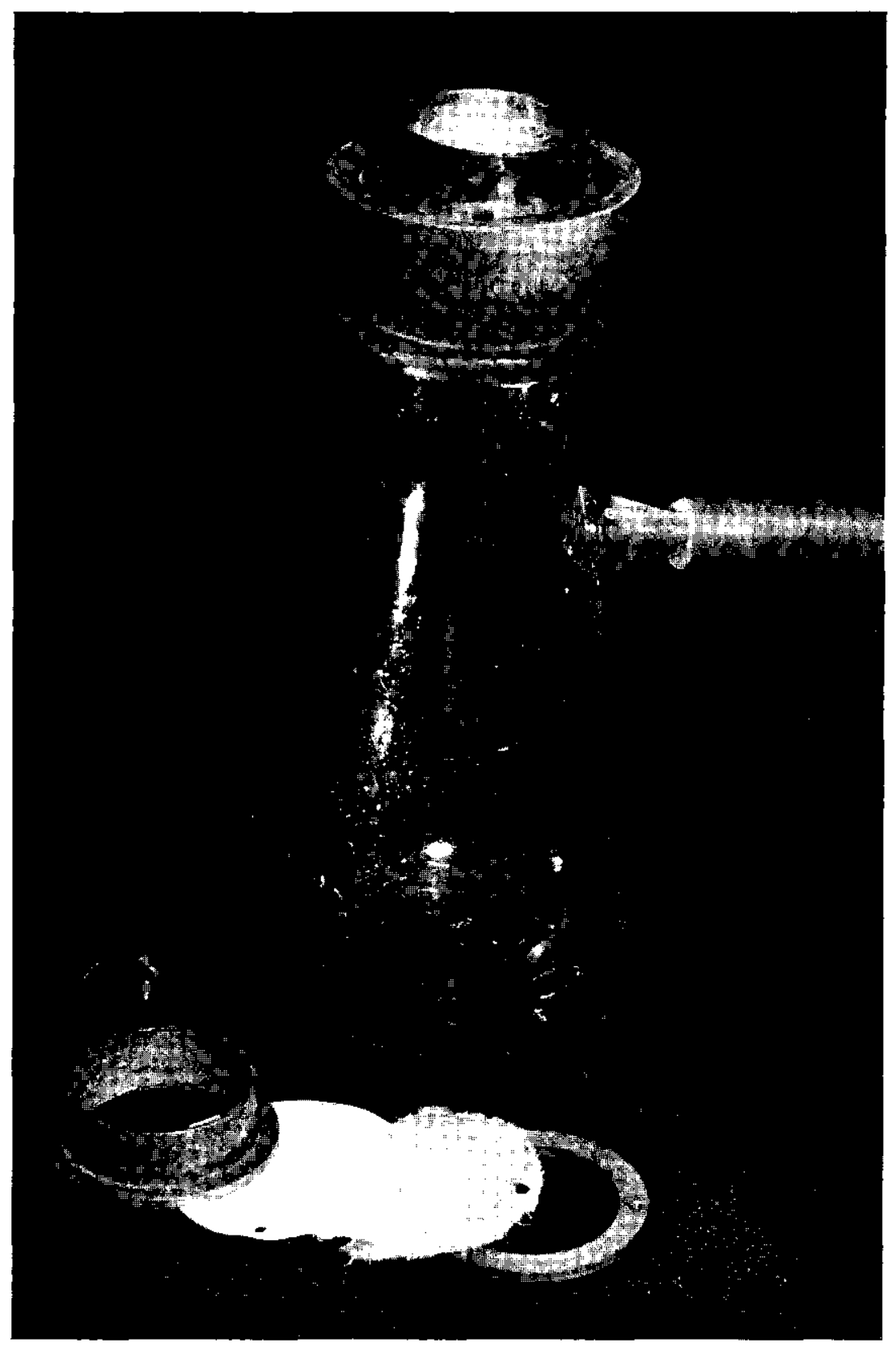

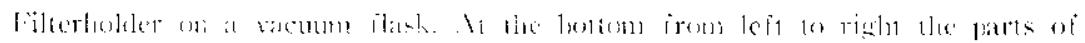

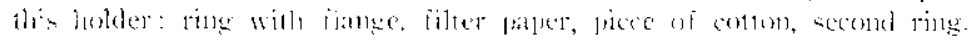




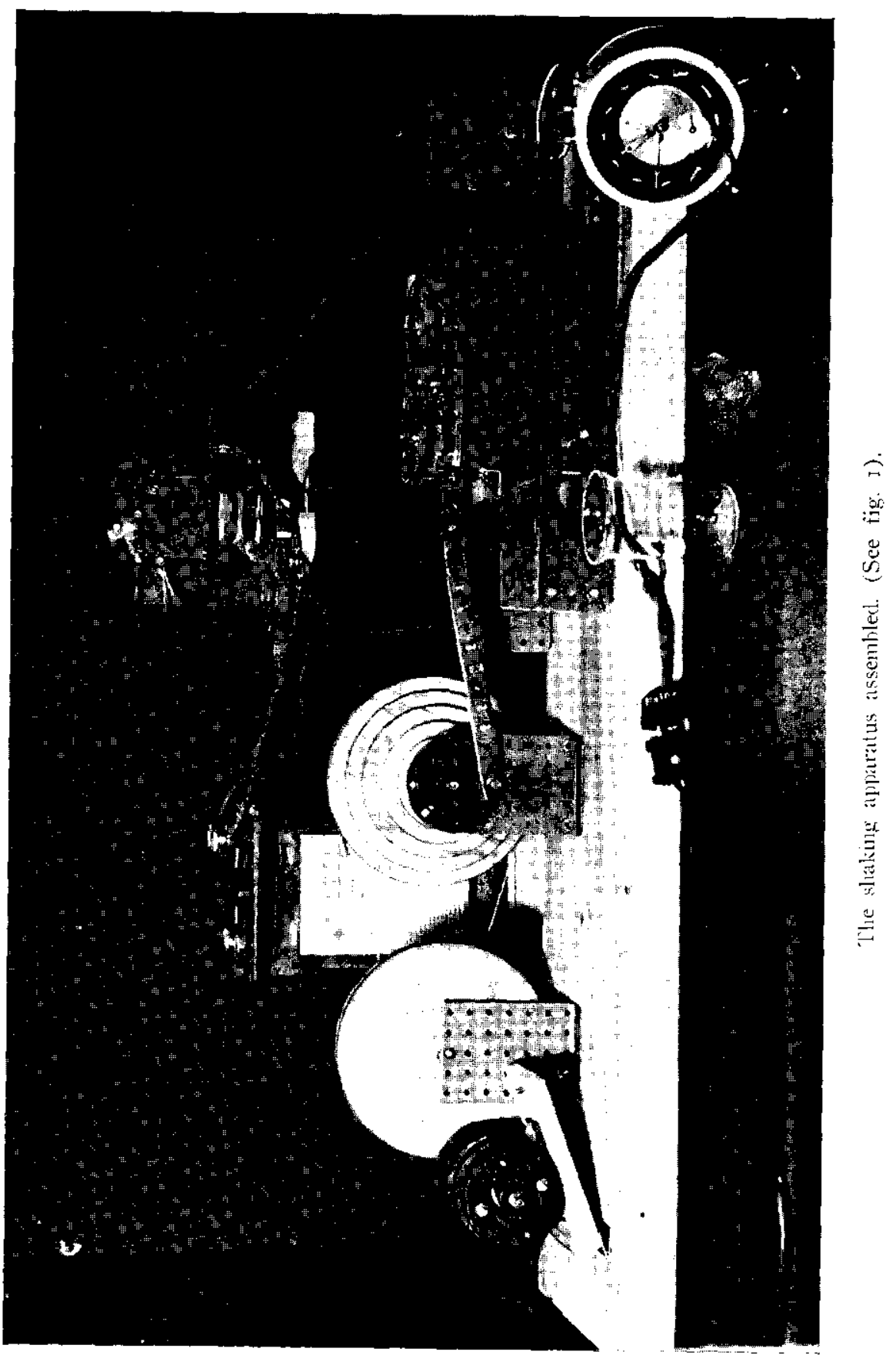


The nematodes are then picked from the residue and placed on microscopic slides with the help of a hair and a binoculair low-power microscope $\left(5^{\circ} \times\right)$.

II. For clay soil.

I. The sample is transferred to a $50 \mathrm{ml}$ centrifuge tube which is filled up to $1 / 4$ or to $1 / 3$ of its volume with the mag. sulph. solution. This tube is clamped under the stirrer, which must revolve at sufficient speed to suspend the particles of the soil sample in the solution. Stirring takes five minutes.

2. The tube is taken from the stirrer, a new quantity of the salt solution is added until the tube is nearly filled and the tube is then placed in the centrifuge for one minute. After about $3^{\text {o seconds the }}$ number of revolutions must be constant at about 1500 revolutions per minute.

3. After centrifuging, the supernatant fluid is poured into a $100 \mathrm{ml}$ centrifuge tube, taking care that the $50 \mathrm{ml}$ tube is rotated on its longitudinal axis to ensure that the fluid adhering to the wall also goes into the $100 \mathrm{ml}$ tube.

4. More mag. sulph. solution is added to the heavy portion which remains in the $50 \mathrm{ml}$ tube, which is now shaken or stirred for a short while followed by centrifuging as in paragraph 2 above.

5. As paragraph 3, using the same $100 \mathrm{ml}$ tube.

6. The $100 \mathrm{ml}$ tube is placed in the centrifuge and rotated for five minutes at a rate of $2500 \mathrm{r} / \mathrm{m}$.

7. After centrifuging, the clear supernatant part of the liquid is poured into a filterholder, taking care that the tube is rotated on its longitudinal axis.

8. More mag. sulph. solution is added to the heavy portion remaining in the tube, which is now shaken or stirred for a short while followed by centrifuging as in paragraph 2 above.

9. As paragraph 7 , using the same filter.

Io. Washing, staining etc.

Numbers of nematodes extracted from samples of different soils by the centrifugal flotation method and found in the residues by the staining method are given in table I. 


\section{TABLE I}

Numbers of nematodes extracted from different soils by centrifugal flotation. Sample size: $1 / 4 \mathrm{ml}$.

Topsoil (uppermost $3 \mathrm{~cm}$ )

from :

Meadow on sand

Meadow on sand

Dry heath on very poor sand

Dry heath on very poor sand

Dry heath on very poor sand

Oak forest on heavy clay over peat 5

Number of nematodes found on the filter II 6 189

16

$\begin{array}{r}9 \\ 34 \\ 59 \\ \hline\end{array}$

423
Number of nematodes found in the residues in the centrifuging tubes ${ }^{1}$ ).

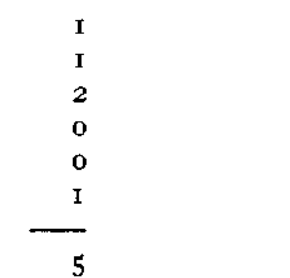

I) Determined by the staining method, using Acid Fuchsin in lactophenol.

COUNTING AND EXTRACTING NEMATODES FROM OAK FOREST LITTER

a. Extraction by intermittent shaking (Modification of the Baermann funnel method)

Besides the number of nematodes in soil, the author wished to determine the number present in oak forest litter, i.e. in leaves in all stadia of humification. The simplest method for the separation of nematodes from such material is the well known Baermann-funneltechnique. The results obtained by this method were, however, not promising. Many days elapsed before nematodes ceased to collect in the stem of the funnel. Also, a number of nematodes probably stayed between the leaves and the presence of an unknown number of eggs gave rise to a new juvenile population. To overcome these difficulties a modification of this technique was designed introducing intermittant shaking.

Procedure.

About Io $\mathrm{g}$ of the material to be examined is cut into pieces of about I sq. cm. From this well-mixed material a small sample of about $300 \mathrm{mg}$ is placed on a piece of copper gauze fastened about $2 \mathrm{~cm}$ from the bottom in a $100 \mathrm{ml}$ beaker (see fig. $\mathrm{I}$ ). This beaker is filled with water op to $1 / 2$ or $2 / 3$ of its volume. The beaker replaces the funnel of the Baermann technique. One to six beakers are placed in the carrier of the apparatus of fig. I and P1. XXII and are shaken periodically for $24 \mathrm{hrs}$. Each period of shaking lasts I minute, followed by 4 minutes of rest. 


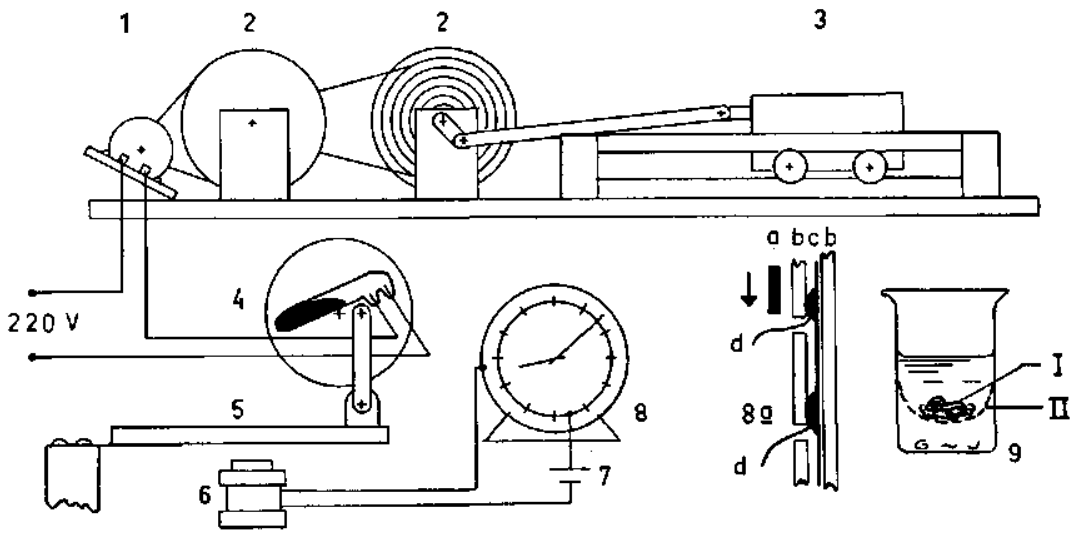

Fig. I. Arrangement of the apparatus in use: 1. Selfstarting motor, 2o Vatt, 220 Volt, $1400 \mathrm{r} / \mathrm{m}$. 2. Stepped pulley, wood, diameter $15 \mathrm{~cm} ., 6$ steps. 3. Shakercarrier moving between two pair of rails. 4. Mercury-switch mounted on a vertical turntable, connected by a lever with the soft-iron bar (5) mounted on a leafspring. 6. electrical magnet connected with a time switch clock (8) via a battery of 4 V. (7). 9. $100 \mathrm{ml}$. beaker partly filled with water. The sample (I) rests on a copper gauze (II). The time switch is a modified alarm clock. The dial-plate is replaced by 2 pieces of plastic, (b) between them a ring of copperwire (c) on which are soldered I2 contact springs (d) which pierce through the uppermost plastic layer and make periodic contact with the minute-hand (d.)

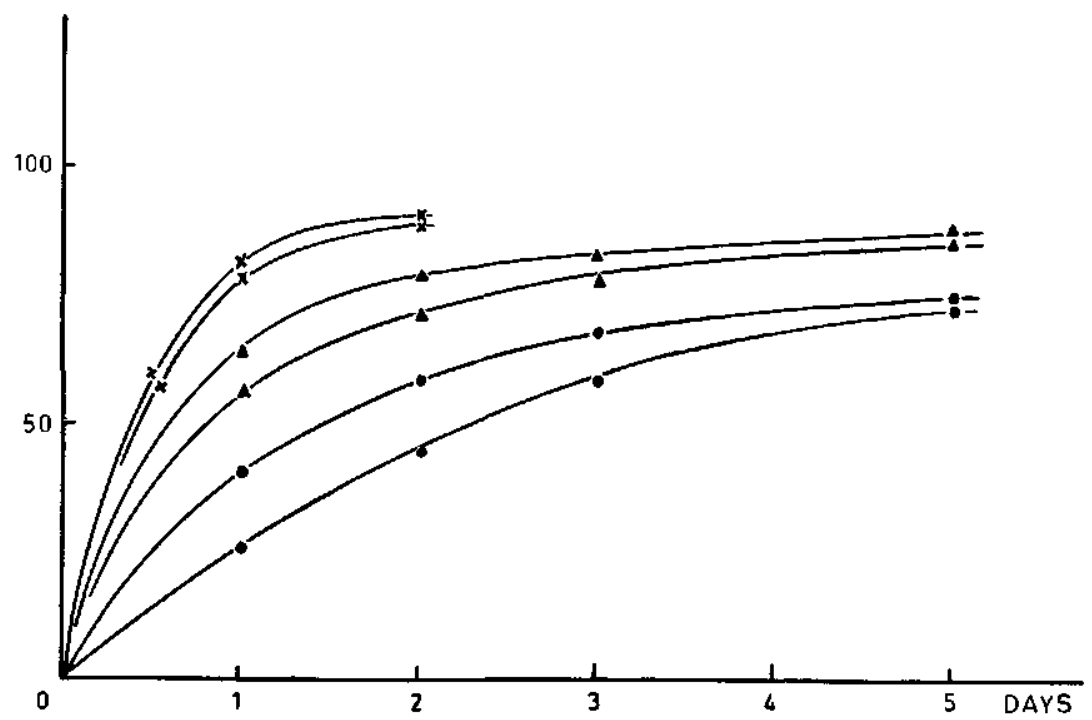

Fig. 2. Results obtained by different techniques. On the ordinate the number of nematodes caught, expressed in \% of the estimated number originally preset.in the sample.

-- Baermann-technique.

- Intermittent shaking, 2 periods of 5 minutes per hovr.

$-\mathrm{x}-$ Intermittent shaking, I2 periods of I minute per hour. 
The amplitude of movement of the carrier is $2.5 \mathrm{~cm}$. and one movement is completed in 3 seconds. If at the end of the shaking period the bottom of the beaker is found to be covered by too much fine material to find the nematodes easily, the whole layer is transferred to a sieve (aperture $50 \mu$ ) which just touches the water surface in a

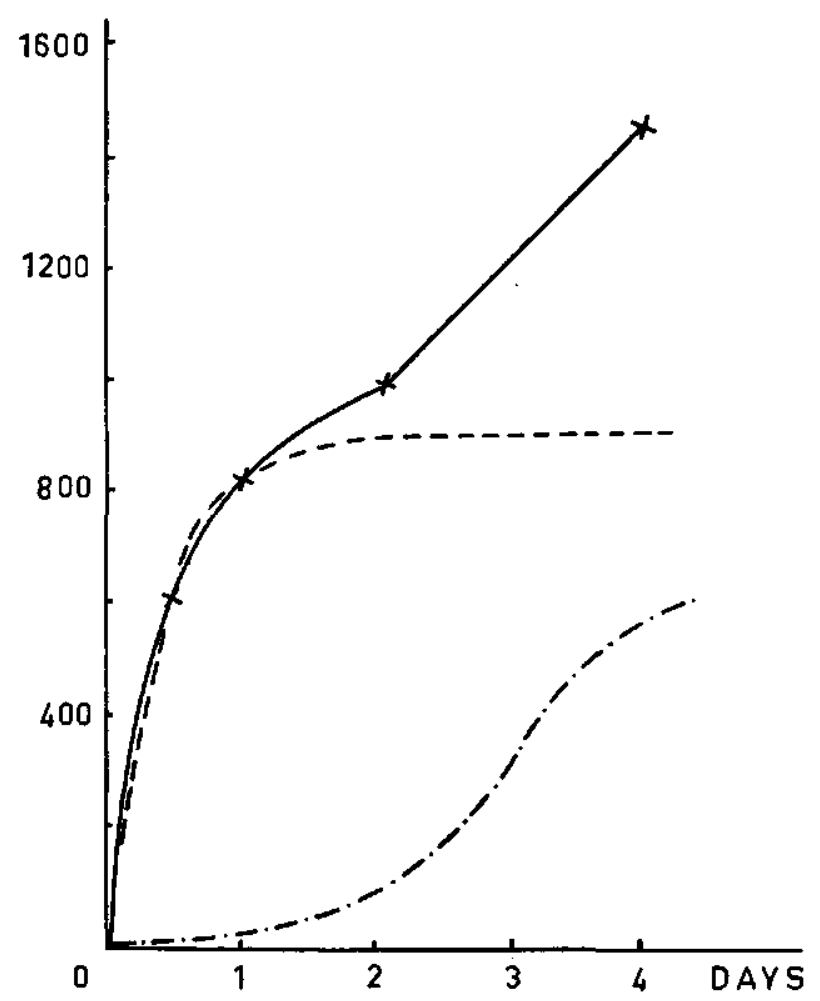

Fig. 3. Diagram to show the derivation of the curve representing the estimated number of newly hatched larvae (- - ) from the curve observed ( - $\longrightarrow$ ) and the hypothetical exponential curve $(--)$ with its asymptotic value $=\mathbf{I}$. Ordinates, the number of nematodes caught in sample $\mathrm{D}$, weight $1050 \mathrm{mg}$ dry litter, taken from the same parent material as the samples A, B, C in fig. I.

Petri-dish. After an hour practically all nematodes will be found in the clean dish.

This method appeared to be the best of those tested methods. Use of the Waring Blendor to cut the leaves into very small particles resulted in halving about $30 \%$ of the nematodes. It was found that by shaking for 5 minutes every half-hour, more nematodes were extracted from samples of the same material than by the Baerman 
funnel method and less than by more frequent shaking (fig. 2). For this reason the technique outlined above was the most satisfactory and it was therefore analysed more closely.

Using Baermann funnels, moss samples (Pleurozium spec.) yielded $50 \%$ of the number of nematodes originally present after 2 hours and $96 \%$ after $\mathrm{I} 8$ hours. The extraction curve approximated closely to that of the exponential function $Y=I-(1 / 2)^{x}$. Extraction of nema-

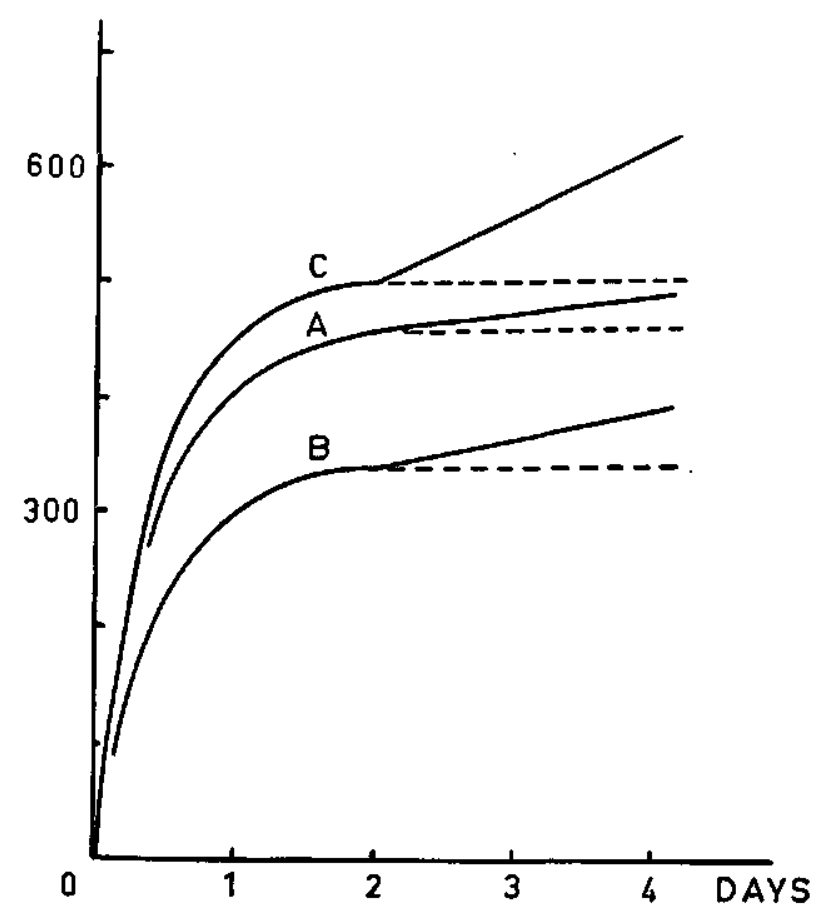

Fig. 4. Three diagrams showing the departure of the observed curve from the hypothetical (- . - -) exponential curve. Ordinates, the number of nematodes in three samples which were taken from the same parent material. Weights of the samples $\mathrm{A}, \mathrm{B}$ and $\mathrm{C}$ resp. 305,288 and $256 \mathrm{mg}$. dry litter respectively.

todes was completed in this case within 24 hours because the moss had no cavities in which the eelworms could stay. The extraction curve for soil samples using the Baermann funnel method was also found to approximate to an exponential function.

In experiments with litter, however, a departure from the exponential curve appeared after 48 hours of extraction (fig. 3,4 ). The author suggests that the extraction curve for nematodes from any 
sample may be represented by the exponential function $\mathrm{Y}=\mathrm{I}$ $(I / 2)^{x}$. If this assumption is correct the curves found for litter may be split into:

a. the hypothetical exponential curve

b. a second curve superimposed over the exponential one and thought to represent the number of newly hatched larvae.

In the example shown in fig. 3 only $I$ adult female occurred in the period between 48 and 96 hours among 498 nematodes found; all others were larvae. Between 24 and 48 hrs the percentage of adults was about $50 \%$. The second curve suggests that in the beginning only a small number of newly hatched larvae disturb the true numbers.

As all the nematodes are not shaken out and collected, the exponential curve obtained is only an approximation of the number originally present. To this number must be added that of nematodes still present in the litter after $96 \mathrm{hrs}$ shaking (for the technique of finding these eelworms see p. 220). In example A (fig. 4) 489 eelworms were collected after $96 \mathrm{hrs}$. and 49 eelworms were found still present in the treated litter. An approximation of the number of newly hatched larvae from the superimposed curve gave 26 . The number originally present should have been $489+49-26=5^{\text {I } 2}$ of which $489-26=463$ i.e. $89 \%$ were collected.

Litter from another situation produced by other plants would give a different percentage of extraction rates.

From the diagrams it appears that after $24 \mathrm{hrs}$ shaking the disturbance due to newly hatched larvae is very small and also that the percentage of the original population collected is rather constant, being $80-82 \%$ in our samples of oak forest litter. This percentage was accepted as constant and the data obtained after 24 hours shaking were multiplied by the factor $\mathbf{I} .25$ to approximate as closely as possible to the number of nematodes originally present in the sample.

The results of 3 tests of the Baermann-technique using samples of the same material, showed that 60 nematodes per Ioo mg litter were found using the latter and I57 eelworms per IOO $\mathrm{mg}$. using the shaking technique. The shaking technique is still somewhat selective, as the species living in the leaves are extracted proportionally less readily than the species living between the leaves. It is possible to identify and to count the numbers still present in the leaves by bleaching and staining them and teasing out the nematodes by means of needles under a low-power binoculair microscope. 


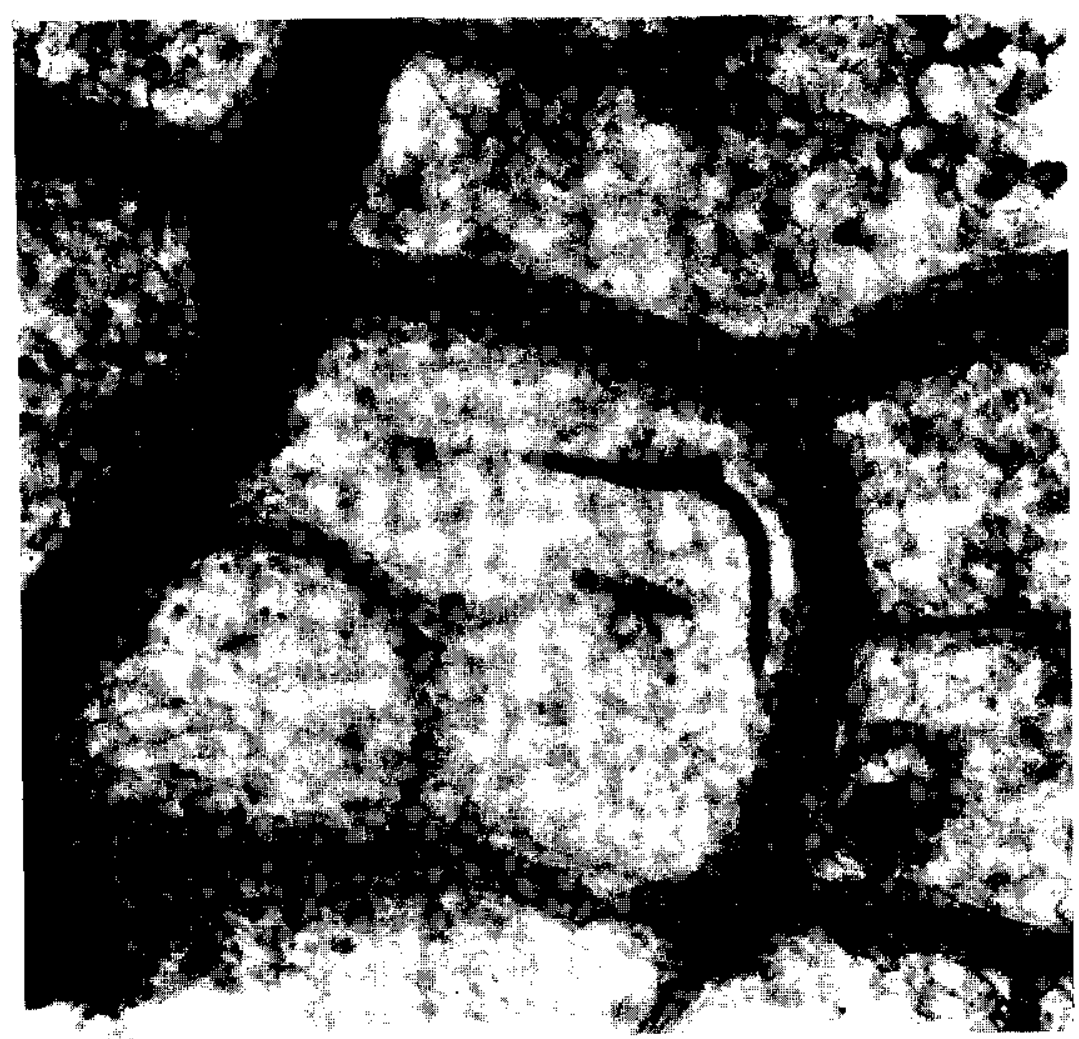

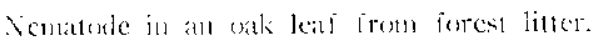


b. Direct microscopical examination of the organisms present in dead oak leaves.

After removing most of the nematodes from oak litter the number still present in the leaves had to be determined. The brown opaque leaves were bleached with hydrogenperoxyde solution and were made transparent by immersing in lactophenol. Nematodes and other organisms (fungi and baceteria) present were stained by means of stains dissolved in lactophenol.

Damp leaves or pieces of them are covered with a mixture containing approximately 3 vol. water, I vol. $20 \%$ ammonia sol., I vol. $30 \%$ hydrogenperoxyde (JoHANsen, 1940).

The bleaching process takes I to 24 hours, dependent on the nature of the material to be bleached. After $24 \mathrm{hrs}$ in the bleaching agent the nematodes can still be satisfactorily stained (Pl. XXIII). The bleached litter is first washed in water and then stained by pouring the hot stain solution $\left( \pm 65^{\circ} \mathrm{C}\right.$ ) over the leaves. After about 5 minutes the dye is poured of $f$ and is replaced by pure lactophenol until no appreciable amount of dye enters into the washing fluid. The objects are mounted in lactophenol and sealed by "Zut".

Stains suitable for our purpose were: 'Trypanblue (B.D.H.), Chlorazol black (I.C.I.), Cottonblue ( $M$ \& B), Vital new red (B.D.H.), Acid Fuchsin (B.D.H.), Violamin IA 3 B (Bayer). Acid Fuchsin and Cottonblue in $0,05 \%$ sol. are most suitable for nematodes. Trypanblue in $0,2 \%$ sol. is excellent for bacteria and fungi, but nematodes become too darkly stained. The other 3 dyes give intermediate results. The following dyes failed: Alizarin, Alkaliblue $6 \mathrm{~B}$, Anilin-violet, Azocarmine G, Azur II, Bengal rose, Biebrichs scarlet, Bismarckbrown Y, Boraxcarmine, Brilliant cresyl blue, Brilliant green, Chrysoidine, Congo-red, Dahlia violet, Fast red, Eosin, Erythrosin, Fuchsin, Gentianviolet, Gossypimine, Haematoxylin, Hexanitrodiphenylamine, Indigocarmine, Janus green, Carmine, Light green, Martius Yellow, Malachite green, Methylene blue, Methylgreen, Methyl-violet BB, Naphtol green B, Naphtol yellow S, Neutral red, Night blue, Nileblue sulphate, Orange G, Phloxin, Rhodanin, Saffranin o, Sudan III, Sudan IV, Thionin, Titan yellow, Tropaeolin ooo, Toluidine blue, Victoria blue.

\section{SUMMARY}

Four different techniques are described by which it appeared possible to investigate the nematode population in samples of soil and litter quantitatively:

I. a. A staining technique. This was the standard method by which it was possible to isolate practically all nematodes from a given sample. 
I. b. Centrifugal flotation: This method took about one eighth of the time required by the foregoing method, but was only slightly less reliable (table I). This technique is based on the fact that nematodes float in a strong magnesium sulphate solution whereas most soil and humus particles sink. The separation of the floating and the sinking fractions is accelerated by centrifuging. Isolation of the nematodes from the small amount of debris in the counting dish takes little time.

2. a. The isolation of nematodes from oak forest litter had to be done in quite another way. The Baermann technique gives an incomplete separation and little reliability. Highly reliable results were obtained by placing a sample in water on a piece of coppergauze in a beaker, and shaking for $\mathrm{I}$ minute followed by 4 minutes of rest, during 24 hours. The number of nematodes caught after 24 hours had to be multiplied by the factor 1.25 to obtain approximately the number of nematodes orginally present in the sample.

2. $b$. The number of nematodes still present in a litter sample after a shaking period of 24 hours was determined after bleaching this material with $6 \%$ hydrogenperoxyde to which some ammonia was added until the leaves were yellowish white. Then followed staining with a hot solution $\left(60-70^{\circ} \mathrm{C}\right)$ of a dye dissolved in lactophenol. Acid fuchsin or cottonblue were more suitable for staining nematodes while trypanblue was found best for bacteria and fungi.

The author wishes to thank Mr. G. C. Moore and Mr. F. G. W. Jones for assistance with English.

\section{REFERENCES}

BaERManN, G. (I9I7), Eine einfache Methode zur Auffindung von Ankylostomium-Larven in Erdproben. - Med. Geneesk. Lab. Weltevreden. Feestbundel.

Goodey, T. (1937), Two methods for staining nematodes in plant tissue. J. Helminth. 15: 137.

Johansen, D. A. (1940), Plant technique. New York and London, Macgraw Hill Minderman, G. (1956), Aims and methods in population researches on soilinhabiting nematodes, - Nematologica I (I) : 47.

StöcklI, A. (I943), Uber Methoden zur quantitativen Bestimmung der im Boden freilebenden Nematoden. - Ber. d. Schw. Bot. Ges. 54 A : I60.

Thorne, G. (1935), Notes on freeliving and plant parasitic nematodes. - Proc. Helminth. Soc. Wash. 2: 98. 